\title{
Strength and Microstructure Analysis of Spot Welded Joints between a Sheet and a Nut of Different Steels
}

\author{
Vytautas JURGAITIS*, Ramūnas ČESNAVIČIUS ${ }^{* *}$, Sigitas KILIKEVIČIUS ${ }^{* * * *}$, \\ Romualdas DUNDULIS $* * * * *$ \\ *Kaunas University of Technology, Studentu 56, 51424, Kaunas, Lithuania, E-mail: v.jurgaitis@ktu.edu \\ **Kaunas University of Technology, Studenty 56, 51424, Kaunas, Lithuania, E-mail: ramunas.cesnavicius@ktu.lt \\ ***Kaunas University of Technology, Studentu 56, 51424, Kaunas, Lithuania, E-mail: sigitas.kilikevicius@ktu.lt \\ ****Kaunas University of Technology, Studentu 56, 51424, Kaunas, Lithuania, E-mail: romualdas.dundulis@ktu.lt \\ cross $^{\text {ref }}$ http://dx.doi.org/10.5755/j01.mech.24.3.21027
}

\section{Introduction}

Spot welding is a widely used process in many industries. This process can be easily automated as it does not require additional components. In the automotive industry, spot welding is used in the entire cycle from joining of body parts to welding of various fasteners. Nuts and bolts for spot welding are designed with embosses which melts during welding in such way producing a welded joint.

Marashi et al. studied dissimilar resistance spot welds between low carbon galvanized and austenitic stainless steels [1]. They studied the relationship between failure mode and weld fusion zone characteristics and found that spot weld strength in the pullout failure mode is controlled by the strength and fusion zone size of the galvanized steel side. The microstructure, fracture and fatigue behaviour of resistance spot-welded cold-rolled high strength austenitic stainless steel was analysed by Liu et al. [2]. It was stated that the improper welding parameters easily caused folding interface in HAZ between welded-sheets. Sometimes determining the quality of a welded joint, the diameter of the weld spot is evaluated. This parameter is strongly influenced by the welding current. The study [3] showed that when the weld current is increased, the spot diameter increases until some certain value is reached. After that value, the diameter decreases due to the excessive melting and splashing.

However, the majority of studies on the strength of spot welding mainly are focused on tensile-shear tests on joints between sheets [4-11]. Burca and Lucaciu [12] investigated joints between standard M8 nuts made of made of E295 steel and thin (up to $3 \mathrm{~mm}$ ) sheets of S235J0 steel by the projection welding method of electric welding by pressure derived from spot welding by pressure to which the joint is made by flanges. However, the tensile test of the joints was not carried out.

As the welding parameters highly affect the welding quality and the materials to be welded, this paper aims to investigate the influence of the welding current on the quality of spot welded joints of a custom nut made of C22 steel and a thin sheet of DC01 steel by carrying out tensile tests, a microstructural analysis and measuring the hardness of the welded contacts.

\section{Experimental set-up}

Eleven specimens, which were welded with three different welding currents, were produced. The specimen with dimensions is shown in Fig. 1.

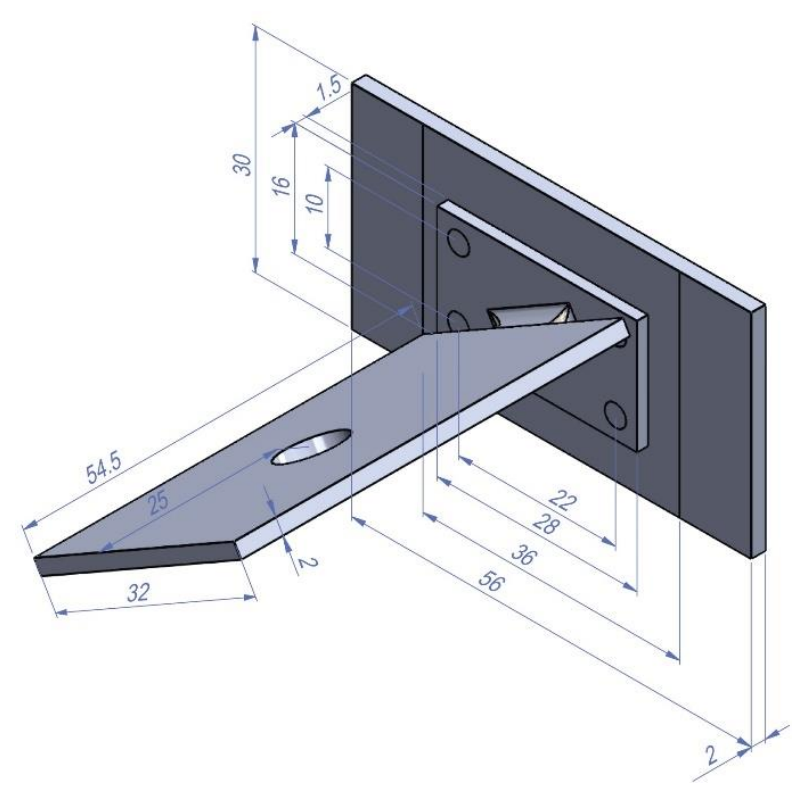

Fig. 1 Specimen with dimensions

A contact welding machine "FASE FS 160-380" (Fig. 2) was used for welding the specimens. The welding process parameters can be changed. They were controlled by a digital controller "F4400 HHT". The controller has a digital display that can easily change the welding parameters and monitor them in real time. The welding parameters were kept constant (the press time before welding was $32 \mathrm{~ms}$, the number of pulses was 1 , the welding time was $3 \mathrm{~ms}$, the press time after welding was $15 \mathrm{~ms}$ and the pressure force was $5 \mathrm{kN}$ ). The spot weld diameter was $2 \mathrm{~mm}$.

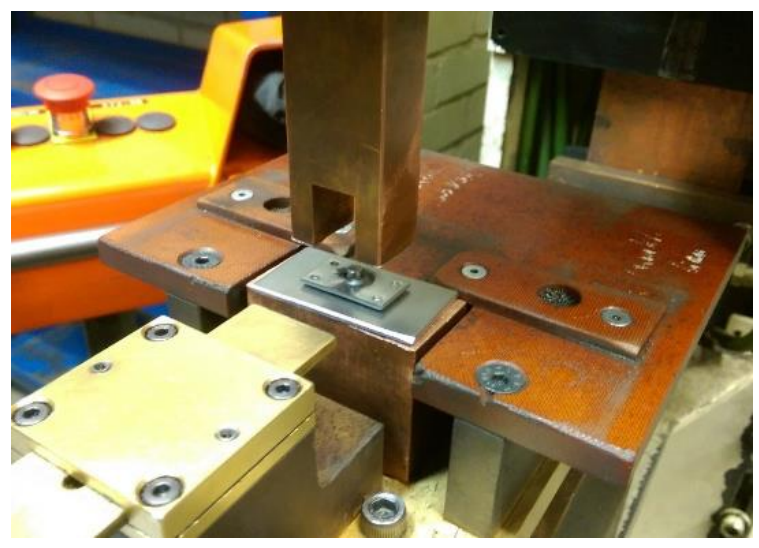

Fig. 2 Contact nuts welding equipment 
Three types of specimens were manufactured, when the welding current $I$ was altered, while the other parameters were kept constant. Four specimens of the first type were welded with a welding current of $9.2 \mathrm{kA}$, four specimens of the second type were welded with a current of $7.5 \mathrm{kA}$, and three specimens of the third type were welded with a current of $9.7 \mathrm{kA}$.

The strength test was carried out using a 25-ton tension-compression machine (Fig. 3).

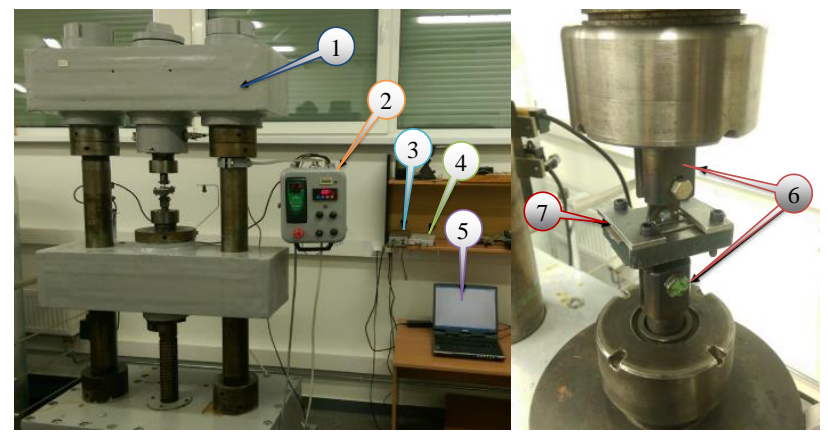

Fig. 3 Experimental setup of strength of spot-welded joints measurement experiments: $1-250 \mathrm{kN}$ tension-compression machine; 2 - control unit of tension-compression machine; 3 - special laboratory charge amplifier; 4 - oscilloscope "Picoscope 3204"; 5 - notebook computer (PC); 6-standard fixing loops; 7 - holder for fixing spot welded joint

The test set-up consists of the $25 \mathrm{t}$ tension-compression machine 1 . Pressure triggering as well as the tension/compression direction can be controlled with the control unit 2. The output signal is transmitted to the special laboratory charge amplifier 3 . The amplifier sends a signal to the oscilloscope 4 "PicoScope 3204", where it is processed and transmitted to the computer 5 through an USB cable. The variation of the tensile force was recorded using "PicoScope 5.12" software. A specimen is attached to the standard fixing device 6 , which can be changed according to the geometry of the specimen. At the top, the specimen is attached to the upper mounting loop. At the bottom of the specimen, the plate is attached to the holder 7 which was specially designed for this test. At the bottom of the holder, there is another plate with a hole, which secures the holder to the standard bottom loop.

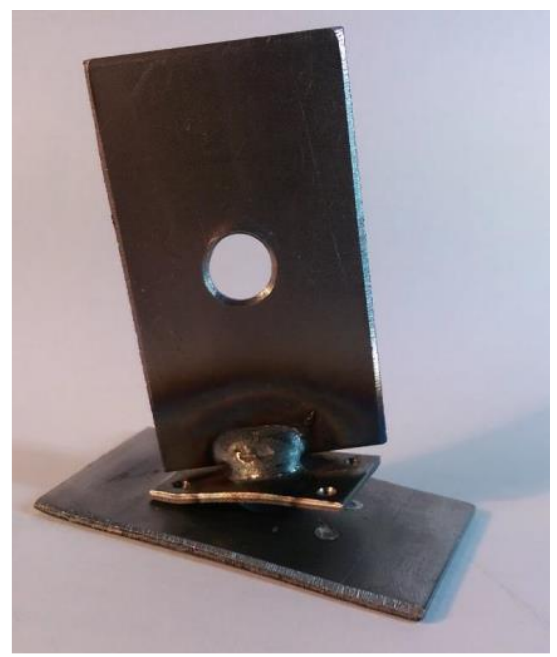

Fig. 4 Specimen after tensile test
The microstructure analysis was performed using a "Carl Zeiss Axio Scope" metallographic microscope. A universal hardness meter "VERZUS 750 CCD" was used to carry out a hardness test. in Fig. 4.

A deformed specimen after the tensile test is shown

The mechanical properties of the DC01 [13] and C22 [14] steels are presented in Table 1.

Table 1

Mechanical material properties

\begin{tabular}{|c|c|c|c|c|}
\hline Material & $\begin{array}{c}\text { Tensile } \\
\text { strength, } \\
\text { ulti- } \\
\text { mate, } \\
\mathrm{MPa}\end{array}$ & $\begin{array}{c}\text { Tensile } \\
\text { strength, } \\
\text { yield, } \\
\mathrm{MPa}\end{array}$ & $\begin{array}{c}\text { Pois- } \\
\text { son's ra- } \\
\text { tio }\end{array}$ & $\begin{array}{c}\text { Modu- } \\
\text { lus of } \\
\text { elastic- } \\
\text { ity, GPa }\end{array}$ \\
\hline $\begin{array}{c}\text { DC01 } \\
(1.0330)\end{array}$ & 280 & 160 & 0.3 & 198 \\
\hline $\mathrm{C} 22$ & 650 & 350 & 0.3 & 201 \\
\hline
\end{tabular}

\section{Tensile strength results}

In Fig. 5, several segments can be distinguished, which are typical for all the obtained curves. In the first part of the graph, the $\mathrm{AB}$ segment shows an increase in the tension force. In $\mathrm{BC}$, the force fluctuation is decreasing until the point $\mathrm{C}$ is reached. In the $\mathrm{CD}$ segment, the force is beginning to increase more rapidly until the critical point $\mathrm{D}$. At the critical point $\mathrm{D}$, the first crack occurs and one of the four spot welds is broken. At this point, the highest value of the tensile force is reached. At the DE segment, there is a decrease in the tensile force, this place deforms the nut plate, and this deformation requires less force. The point $\mathrm{E}$ indicates that the remaining welding points are being stretched further. Finally, at the point $F$, the ultimate tensile force of another weld point is reached and the welding point is broken. The force drops to the point G. At the segment FG, the nut plate deformation continues until, at the point $\mathrm{G}$, the remaining two spot welds are being stretched further.

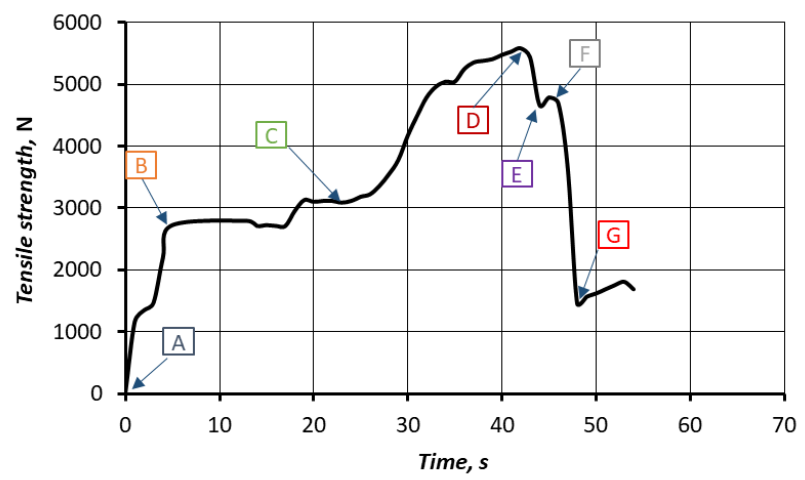

Fig. 5 The curve of force variation in time with marked points

The results of the tensile test are shown in Fig. 6. The averaged curves are given for each of the specimen types welded under the investigated values of welding current. 


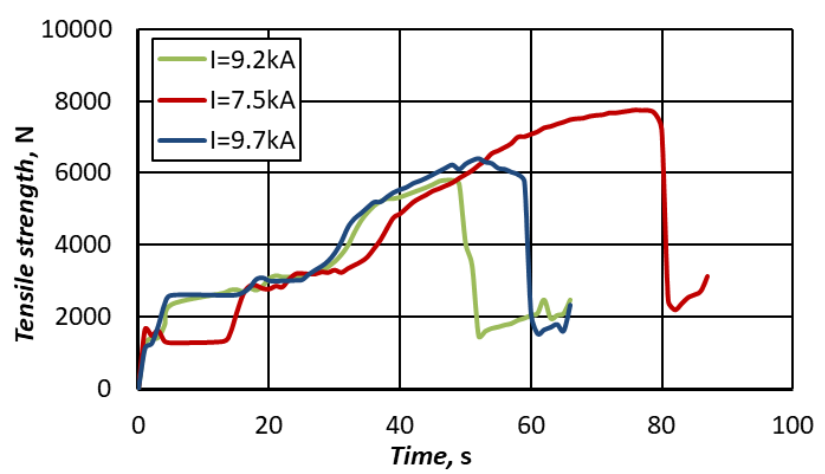

Fig. 6 Tensile test results

It was found that the specimens welded with a current of $7.5 \mathrm{kA}$ were able to withstand a longer time and broke down at $7749 \mathrm{~N}$. Meanwhile, the specimens welded with a higher welding current broke down with a lower tensile force $(5808 \mathrm{~N}$ when the welding current was $9.2 \mathrm{kA}$ and $6402 \mathrm{~N}$ when it was $9.7 \mathrm{kA}$ ).

\section{Microstructure analysis}

A microstructural analysis was carried out to determine and compare the quality of the welded joints welded with different parameters.

Three zones of microstructure can be distinguished by examining the specimens. The first one is the base metal (BM), in this case it is the plate to which the non-standard nut was welded. The second zone is the welded nut (WN). The third zone is the molten metal (FZ) between the nut and the plate, where the merging process takes place.

In the case of the first sample (Fig. 7), when the welding current is $9.2 \mathrm{kA}$, it is seen that the asymmetry of the central FZ zone appears. Most often, this phenomenon occurs due to the different thermal properties of metals, since the nut and the test plate are made of different steel. Another cause of asymmetry can be the different geometry of the elements. In this case, we conclude that the nut material has a higher thermal conductivity than the part's material.

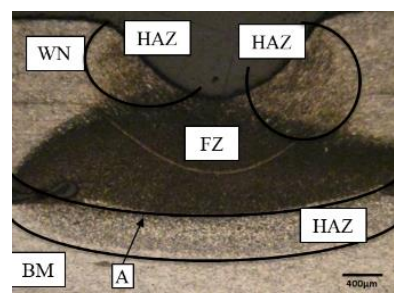

a

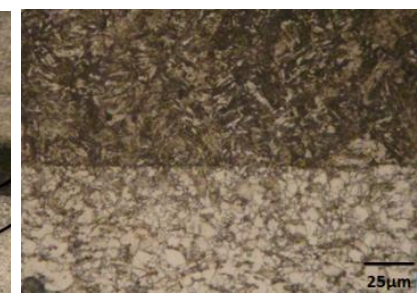

$\mathrm{b}$
Fig. 7 View of the first type of specimen: $a-$ the main microstructure; $\mathrm{b}$ - zone A of microstructure view

After examining the welding, a line is visible which indicates the transition from the zone FZ to the heat affected zone (HAZ), as shown in Fig. 7, a. This zone is marked with the letter A and shown in Fig. 7, b.

When evaluating the second type of specimens with a welding current of $7.5 \mathrm{kA}$, we can distinguish the same zones as in the first sample. As shown in Fig. 8, a the FZ zone is asymmetric as in the first sample.

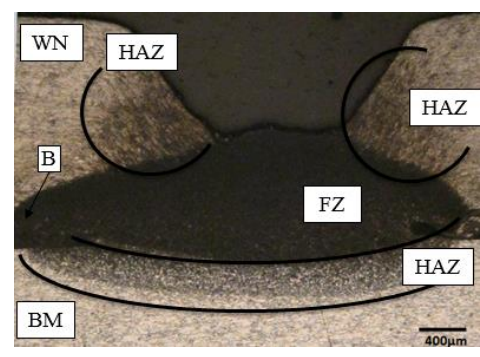

a

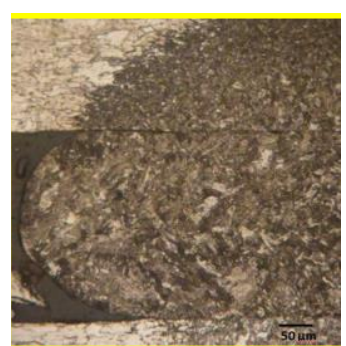

b
Fig. 8 View of the second type of specimen: $a-$ the main microstructure; $\mathrm{b}$ - zone $\mathrm{B}$ of microstructure view

The HAZ area is larger on the nut side, but it is seen that in this specimen the HAZ area on the side of the part is smaller than in the first sample. Fig. 8, a shows a welding defect, i.e. the hollow cavity. This zone is marked with letter $\mathrm{B}$ and shown in Fig. 8, b.

In addition to the formation of separate metal structures that do not connect with the rest of the sample, it shows that there was an explosion in the metal in this area. The formation of this zone affects the strength of the welded joint. When the metal is thermally exposed, when structural changes occur, internal stresses are formed inside it, which may lead to the formation of micro-cracks after reaching a certain limit. Fig. 8 shows the lines, which are micro-cracks in the material.

During the welding process, high amounts of heat are released. Heat-affected materials change their properties, one of these properties is the hardness of material. These changes can influence the strength of the weld, therefore, measurements of the hardness of the welded point were done in this study.

After the microstructure analysis, the hardness of the material was measured at the location of welding zone. The Vickers hardness test was carried out, i.e. the quadrilateral diamond pyramid is pressed into the sample. The measurement of distances between the angles of the pyramid was done and calculation of the hardness of the material was performed.

The first type of specimens, welded at $9.2 \mathrm{kA}$, had the highest hardness at the FZ area and is equal to $476.9 \mathrm{HV}$ units. The point of highest hardness in the first type of specimens is shown in Fig. 9, a. The second type of specimens, welded at $7.5 \mathrm{kA}$, had the highest hardness at the FZ area and it was equal to $422.1 \mathrm{HV}$ units. The point of highest hardness in the second type of specimens is shown in Fig. 9, b.

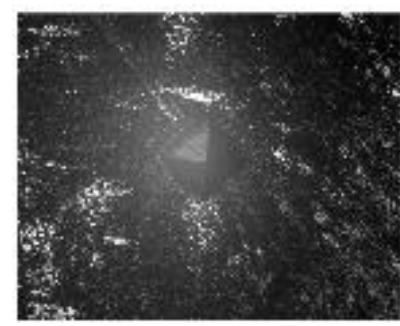

a

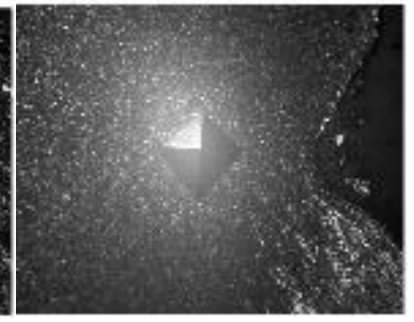

b
Fig. 9 View of hardness measurement: $\mathrm{a}$ - the point of highest hardness in the first type of specimens; $b$ - the point of highest hardness in the second type of specimens 


\section{Numerical simulation of the spot welded joints re- sponse to tension}

The spot welded joints response to tension was investigated numerically in ABAQUS/EXPLICIT software using a 3D model (Fig. 10) of the same geometrical parameters as the specimens used for the experiments.

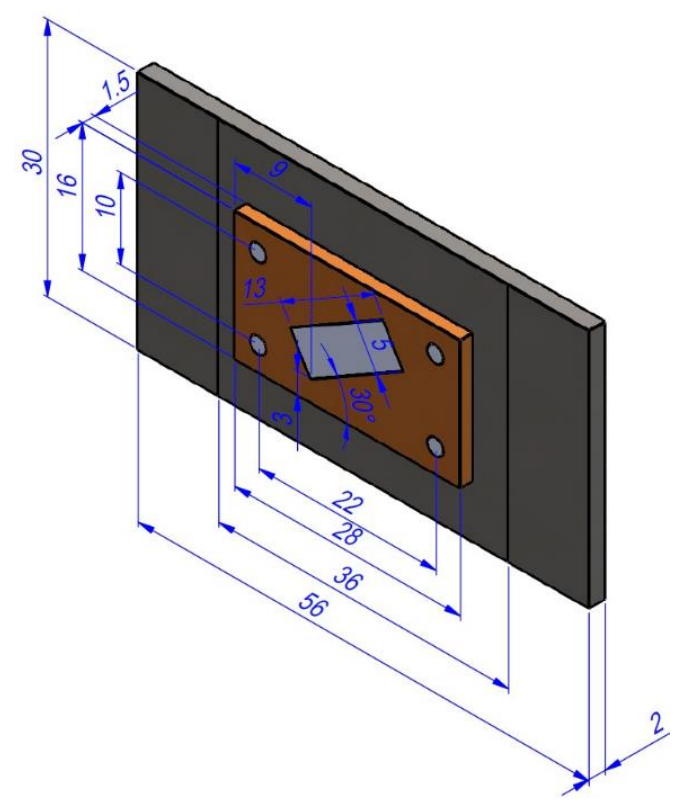

Fig. 10 Geometrical parameters of the 3D model of the spot welded joint

The components of the welded joint were meshed using element type C3D8R. An element size of $0.1 \mathrm{~mm}$ was used in the areas of the spot welds while the most distant areas were meshed using an element size of $1 \mathrm{~mm}$, accordingly, the mesh contained 107930 elements. The spot weld features were connected to the components using tie constraints. A prescribed displacement in tension was defined on the nut plate. The mesh and the boundary conditions are shown in Fig. 11.

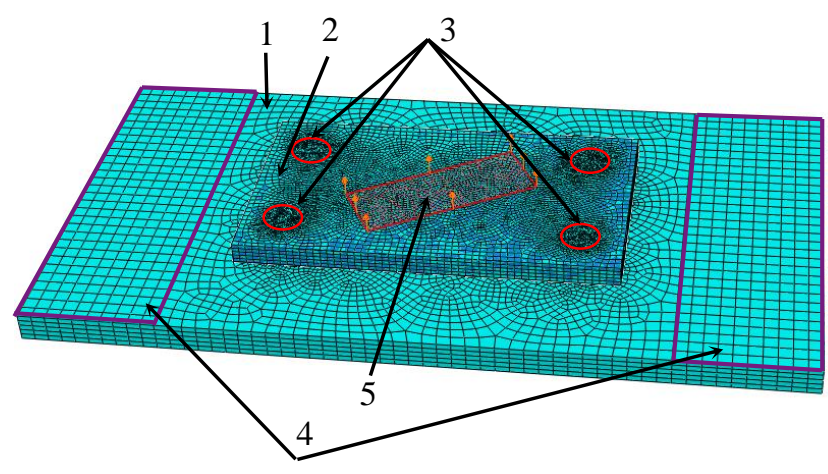

Fig. 11 Mesh and boundary conditions: 1 - DC01 steel sheet; 2 -C22 steel nut plate; 3-spot welds; 4 - clamped surfaces; 5 - surface with a prescribed displacement in tension

In dynamic explicit analysis, it was assumed that the materials are homogeneous and isotropic by defining the moduli of elasticity and Poisson's ratios given in Table 1. The von Mises yielding criterion and isotropic hardening were used to simulate the plastic response of the components applying the true stress-strain curves of DC01 [13] and C22 [14] steels. For simplification the heat affected zones around the spot welds were not defined in the model. The ductile damage initiation criterion was used in this study. The failure strain as a function of stress triaxial state and equivalent plastic strain in the model was considered. The failure strain values from the true stress-strain tensile curves were used to govern damage initiation, 0.38 [13] and 0.5 [14] for DC01 and C22 steels, respectively.

\section{Results of the numerical simulation}

The simulation showed that the failure occurs in the DC01 sheet as it has lower mechanical properties. Figs. 12 and 13 show the equivalent plastic strain and the von Mises stress in the DC01 sheet after the breaking of all the spot welds, respectively. The maximum displacement of the DC01 sheet was $1.8 \mathrm{~mm}$ and the deformed shape is very similar to the deformed experimental specimens.
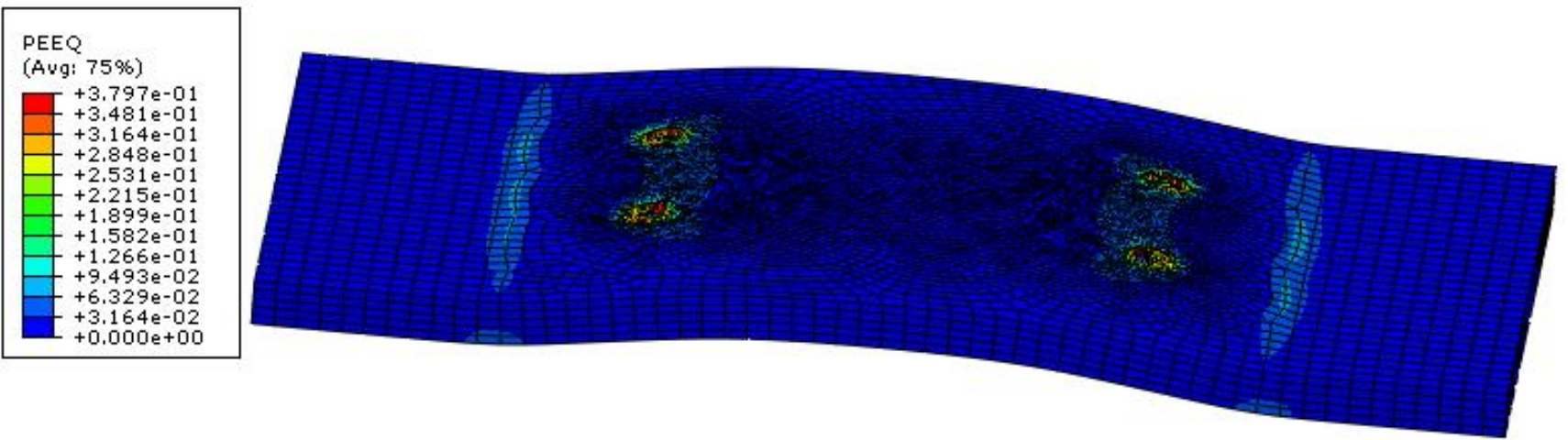

Fig. 12 Equivalent plastic strain in the DC01 sheet after the breaking of all the spot welds 

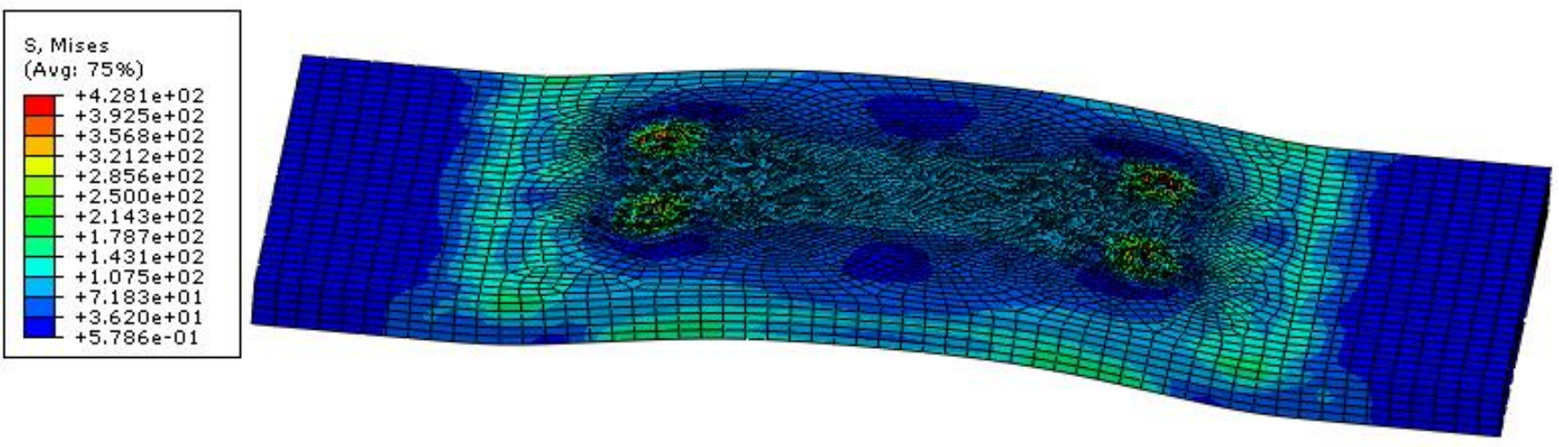

Fig. 13 Von Mises stress (MPa) in the DC01 sheet after the breaking of all the spot welds

The variation of the tensile force during tension under prescribed displacement is presented in Fig. 14.

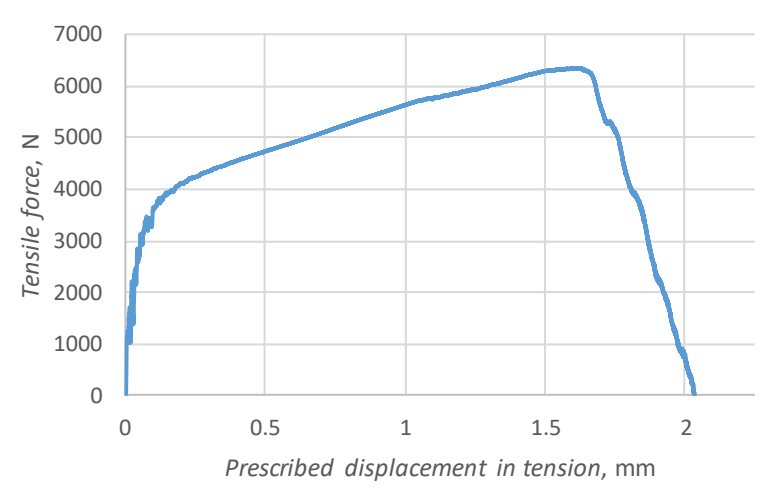

Fig. 14 Tensile force vs prescribed displacement in tension

The profile of the simulated tensile force is very similar to the profile of the experimental curves (Fig. 5). The maximum force value was $6296 \mathrm{~N}$, which corresponds to the specimen welded with the current of $9.7 \mathrm{kA}$.

\section{Conclusions}

Investigation of the strength of welded specimens was carried out. It was found that the specimens welded with a current of $7.5 \mathrm{kA}$ were able to withstand a higher tensile force of $7749 \mathrm{~N}$.

Microstructure study of welded specimens was carried out as well. The microstructure of the specimens was analysed and the welding contact zones were determined. The welding contact zone was found to be asymmetric since the materials have different thermal conductivity. This material parameter has a major influence on the asymmetry of the welded area. It has also been found that welding with a higher welding current leads to more micro-cracks.

Considering the obtained results, it can be stated that among the tested welding currents, $7.5 \mathrm{kA}$ is the most preferable as it results in less micro-cracks and the highest strength of the joint.

A numerical simulation of the spot welded joints response to tension was carried out and showed that the investigated spot welded joint was broken under $6296 \mathrm{~N}$, this corresponds to the specimen welded with the current of 9.7 kA. The profile of the simulated tensile force is very similar to the profile of the experimental curves.

\section{References}

1. Marashi, P., Pouranvari, M., Amirabdollahian, S., Abedi, A., Goodarzi, M. 2008. Microstructure and failure behavior of dissimilar resistance spot welds between low carbon galvanized and austenitic stainless steels. Materials science and engineering: A, 480(1-2), 175180. https://doi.org/10.1016/j.msea.2007.07.007.

2. Liu, W., Wang, R., Han, J., Xu, X., Li, Q. 2010. Microstructure and mechanical performance of resistance spot-welded cold-rolled high strength austenitic stainless steel. Journal of Materials Processing Technology, 210(14), 1956-1961. https://doi.org/10.1016/j.jmatprotec.2010.07.008.

3. Vural, M., Akkuş, A., Eryürek, B. 2006. Effect of welding nugget diameter on the fatigue strength of the resistance spot welded joints of different steel sheets. Journal of Materials Processing Technology, 176(1-3), 127-132. https://doi.org/10.1016/j.jmatprotec.2006.02.026.

4. Pouranvari, M., Mousavizadeh, S. M., Marashi, S. P. H., Goodarzi, M., Ghorbani, M. 2011. Influence of fusion zone size and failure mode on mechanical performance of dissimilar resistance spot welds of AISI 1008 low carbon steel and DP600 advanced high strength steel. Materials \& Design, 32(3), 1390-1398. https://doi.org/10.1016/j.matdes.2010.09.010.

5. Pouranvari, M., Marashi, S. P. H. 2011. Failure mode transition in AHSS resistance spot welds. Part I. Controlling factors. Materials Science and Engineering: A, 528(29-30), 8337-8343. https://doi.org/10.1016/j.msea.2011.08.017.

6. Pouranvari, M., Marashi, S. P. H., Safanama, D. S. 2011. Failure mode transition in AHSS resistance spot welds. Part II: Experimental investigation and model validation. Materials Science and Engineering: A, 528(29-30), 8344-8352. https://doi.org/10.1016/j.msea.2011.08.016.

7. Qiu, R., Iwamoto, C., Satonaka, S. 2009. Interfacial microstructure and strength of steel/aluminum alloy joints welded by resistance spot welding with cover plate. Journal of Materials processing technology, 209(8), 4186-4193. https://doi.org/10.1016/j.jmatprotec.2008.11.003.

8. Charde, N. 2012. Characterization of spot weld growth on dissimilar joints with different thicknesses. Journal of Mechanical Engineering and Sciences, 2(unknown), 
172-180.

http://dx.doi.org/10.15282/jmes.2.2012.4.0015.

9. Aslanlar, S. 2006. The effect of nucleus size on mechanical properties in electrical resistance spot welding of sheets used in automotive industry. Materials \& Design, 27(2), 125-131. https://doi.org/10.1016/j.matdes.2004.09.025.

10. Khandoker, N., Takla, M. 2014. Tensile strength and failure simulation of simplified spot weld models. Materials \& Design (1980-2015), 54, 323-330. https://doi.org/10.1016/j.matdes.2013.08.070.

11. Saha, D. C., Han, S., Chin, K. G., Choi, I., Park, Y. D. 2012.. Weldability Evaluation and Microstructure Analysis of Resistance-Spot-Welded High-Mn Steel in Automotive Application. Steel research international, 83(4), 352-357. https://doi.org/10.1002/srin.201100324.

12. Burcă, M.; Lucaciu, I. 2013. Research on Weld Nuts Fixed by Resistance Welding. Annals of the Oradea University. Fascicle of Management and Technological Engineering. Issue \#3. 15-20. https://doi.org/10.15660/AUOFMTE.2013-3.2945.

13. Wang, L.; Long, H.; Ashley, D.; Roberts, M.; White, P. 2011. Effects of the roller feed ratio on wrinkling failure in conventional spinning of a cylindrical cup. Proceedings of the Institution of Mechanical Engineers Part B-Journal of Engineering Manufacture, 225(B11), 19912006. https://doi.org/10.1177/0954405410396024.

14. Dorogoy, A., Rittel, D., Godinger, A. 2016. A sheartension specimen for large strain testing. Experimental Mechanics, 56(3), 437-449.

https://doi.org/10.1007/s11340-015-0106-1.
Vytautas JURGAITIS, Ramūnas ČESNAVIČIUS, Sigitas KILIKEVIČIUS, Romualdas DUNDULIS

\section{STRENGTH AND MICROSTRUCTURE ANALYSIS OF SPOT WELDED JOINTS BETWEEN A SHEET AND A NUT OF DIFFERENT STEELS}

S u m m a r y

This study presents an investigation on the strength of spot welded joints between a plate made of DC01 steel and a non-standard nut made by cold forming of C22 steel. In order to determine the influence of the welding current on the quality of such welded joints, three types of test specimens were produced using different welding currents. The strength of the welded joints was studied and microstructural analysis was carried out as well as the hardness of the welded contacts was measured. A numerical simulation of the spot welded joints response to tension was carried out and the results were consistent with the experiments.

Keywords: spot welding, welded joints, welding parameters.

Received May 30, 2018

Accepted June 25, 2018 